\title{
Identifying enablers for future e-Services
}

\author{
Martin Böcker \\ Böcker \& Schneider GbR \\ Konstanze, Germany \\ Helge Hüttenrauch \\ Royal Institute of Technology (KTH) \\ Stockholm, Sweden \\ Michael Pluke \\ Castle Consulting Ltd. \\ Ipswich, England \\ Mike.Pluke@Castle-consult.com
}

\author{
Alejandro Rodriguez-Ascaso \\ aDeNu research group / UNED \\ Barcelona, Spain \\ Matthias Schneider \\ Böcker \& Schneider GbR \\ Munich, Germany \\ Erik Zetterström \\ Omnitor AB \\ Stockholm, Sweden \\ Erik.Zetterstrom@Omnitor.se
}

\begin{abstract}
The starting point of the project is the observation that new information and communication technologies (ICT) are often introduced without taking into account the requirements of elderly and/or disabled users, resulting in products and services that are hardly usable by those users. A method for identifying enablers for future e-Services is described. In short it identifies usability problems with future interation technologies and map these future interaction technologies to e-Services. The results of investigations using this method allow stakeholders in different stages of the research and development lifecycle e-Services to spot potential difficulties in the design of user interfaces which could cause elderly or disabled users to experience usability issues.
\end{abstract}

Keyword; Design for All; Accessibility of novel interactive systems; technology roadmap; standardisation, ETSI

\section{INTRODUCTION}

This Information and Communication Technologies (ICT) have the potential of facilitating the lives of most users, including those of elderly and disabled people. However, a European Union study from 2005 conducted in 14 European concluded that despite increasing levels of ICT usage in all sections of society, the digital divide is not being bridged [1]. This state of affairs can be attributed to a number of frequentlyobserved obstacles to the accessibility of ICT devices and

The work on future e-Services presented in this paper is performed at European Telecommunications Standards Institute (ETSI) [2] by the members of the Specialist Task Force (STF) 377 [3] under the guidance of the ETSI TC HF (Human Factors). ETSI produces globally-applicable standards for Information and Communications Technologies (ICT), including fixed, mobile, radio, converged, broadcast and internet technologies and is officially recognized by the European Commission as a European Standards Organization. ETSI is a not-for-profit organization whose 720+ ETSI member companies and organizations benefit from direct participation and are drawn from 60 countries worldwide. ETSI Specialist Task Forces (STF) [4] are teams of highly-skilled experts working together over a pre-defined period to draft an ETSI standard under the technical guidance of an ETSI Technical Body and with the support of the ETSI Secretariat. The task of the STFs is to accelerate the standardization process in areas of strategic importance and in response to urgent market needs. The work on personalization presented in this paper is co-financed by the EC/EFTA in response to the EC's ICT Standardisation Work Programme

PERVASIVEHEALTH 2010, March 22-25, Munchen, German

Copyright $\odot 2010$ ICST 978-963-9799-89-9

DOI 10.4108/ICST.PERVASIVEHEALTH2010.8886 services.

Experience consistently shows that user-interface innovations for consumer products are being researched, developed, and introduced without taking into account the needs of people with mild or severe impairments such as elderly people. Many companies do not see a business case in offering barrier-free products.

Product and service developers are often unaware of the requirements of customers with impairments, nor are they familiar with appropriate design solutions that may not be very demanding in terms of $\mathrm{R} \& \mathrm{D}$ and production costs.

For most user-interface design tasks, a number of different solutions exist that differ in terms of their suitability for different user groups, which in some cases could be very narrowly defined commercial target groups. A more general user-interface design approach encompasses the selection and combination of various user-interface modalities with the goal of supporting the most diverse user community possible.

Design for all should not be conceived as an effort to advance a single solution for everybody, but as a user-centred approach to providing environments designed in such a way that they cater for the broadest possible range of human needs, requirements and preferences, see [5].

\section{BACKGROUND}

Historically the pattern is that the requirements of elderly people and people with disabilities lag significantly behind the initial availability of innovative new technologies. This pattern is so common because new applications and sometimes disruptive technologies have in the past been developed for and targeted at mainstream consumers and frequently at welldefined target groups of early adopters e.g. the wealthy (in the case of the TV) or the technology-aware (as in the case of the $\mathrm{PC}$ or the Internet). Those technologies did not include the easy 
accommodation of the requirements of people with disabilities. Subsequent measures for compensating these shortcomings have often been late and costly. Listed below are some examples of the inadequate introduction of new technologies:

1. Personal computer (PC): The first PCs with character-based user interfaces were easily usable by blind users with a Braille-reader device. The advent of graphical user interfaces (GUI) suddenly excluded blind users.

2. Document file formats Documents produced in earlier graphics-based versions of the PDF-format were not accessible to blind users.

3. The Internet The problems are similar to the ones described for the PC, as early computer services (e.g. gopher services and first E-mail services) were text based and later replaced by graphical interfaces such as web browsers. The Web Accessibility Initiative (WAI) stepped in late, and took long to evolve if compared to the very dynamic development of web technologies.

4. MP3/media players Many classic cassette players have mechanical switches and mechanisms that rely on the physical insertion and turning of a cassette to select different audio segments. However, modern MP3 players are increasingly relying on on-screen interfaces with few, if any, physical controls to offer suitable feedback and are therefore unsuitable for people with poor eyesight.

5. Biometric systems Biometric applications are more and more used for supporting authorization and access control. People with disabilities (e.g. physical or speech impairments) are likely to face barriers as users of these systems. Multimodality may contribute to accessibility in this field, as well as to higher levels of performance and user acceptance.

It is likely that the conception and development of forthcoming interaction technologies, such as natural-language input, gesture recognition, haptic and tactile interfaces will follow a similar pattern.

Previous publications have produced an excellent basis for educating device and service designers about the requirements of older users and users with disabilities and for illustrating inclusive design for accessible eServices (see e. g. [6] for a detailed overview of design-for-all requirements for telecommunications products and services). However, the current literature focuses on existing technologies. The developers of innovative new technologies may be unaware of these resources and, if they are, it may not be easy for them to apply guidance from them to the development of new technologies.

There is a need for an analysis that anticipates the demands of new interaction technologies and for the provision of appropriate guidance in the form of design guidelines that document in which ways users with different abilities will be affected by a new technology and how accessibility obstacles can be overcome.

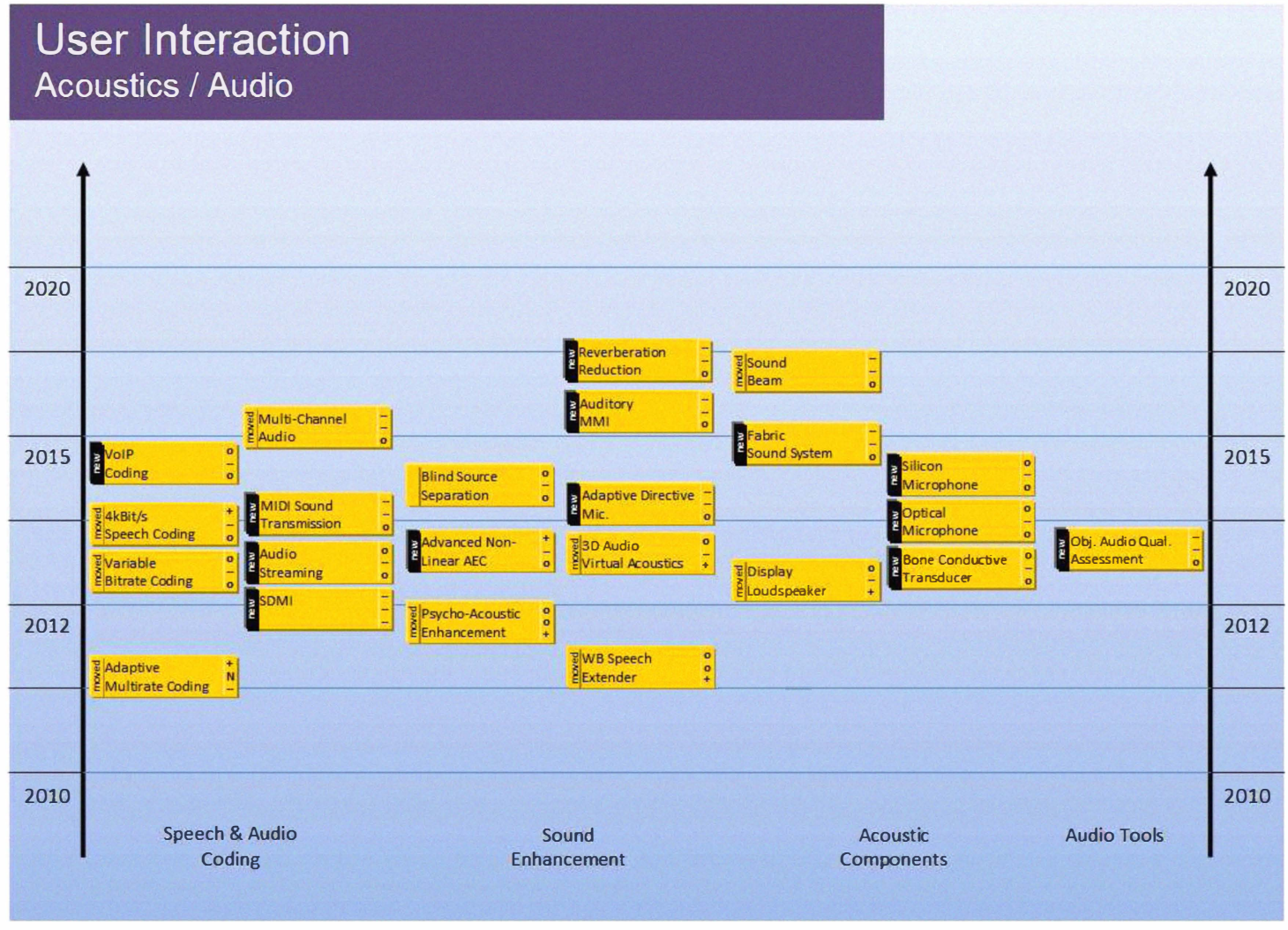

Figure 1. Example technology roadmap 


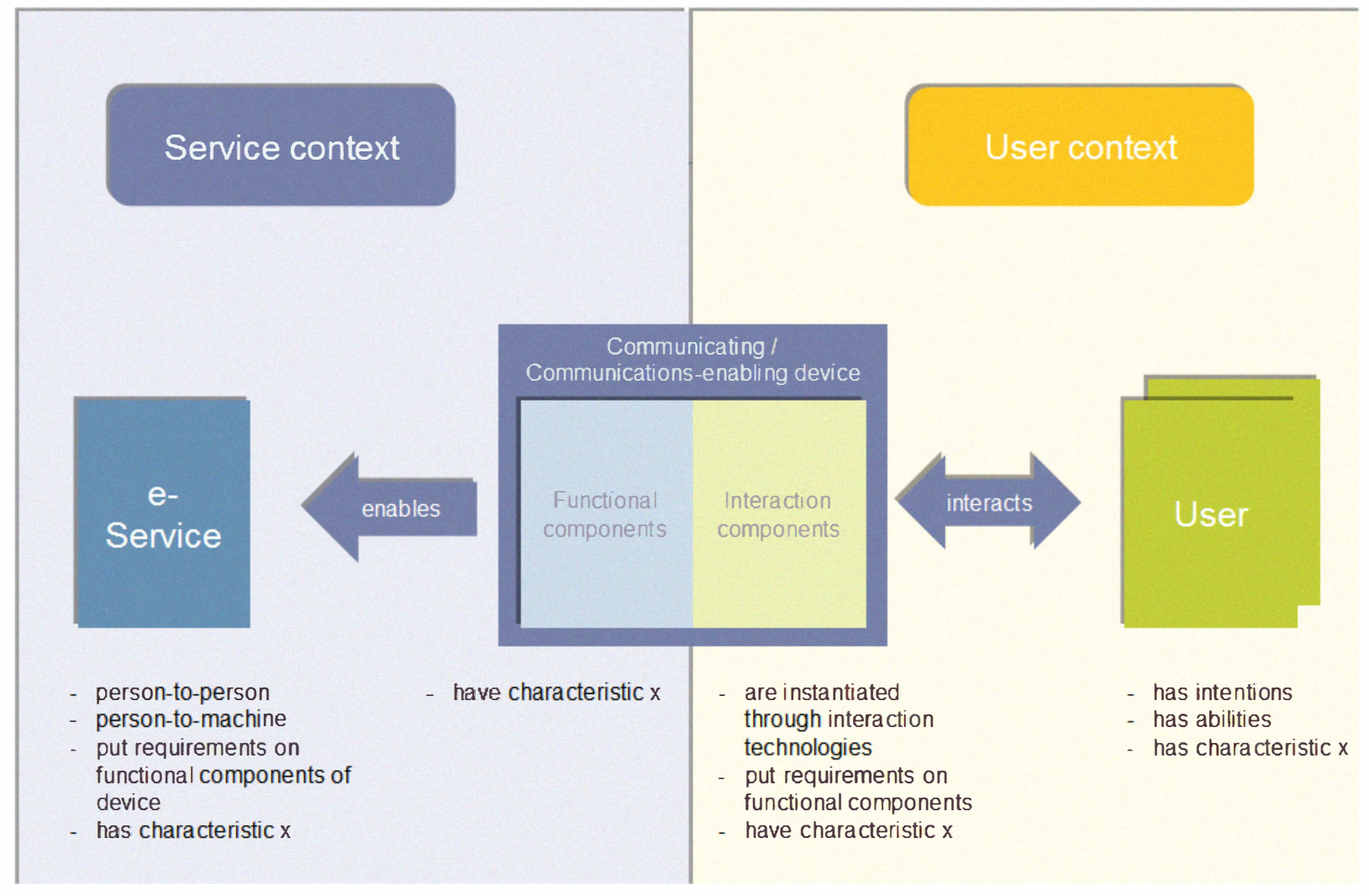

Figure 2. Conceptual framework contrasting User and Service Contexts

\section{METHOD}

The method focuses on the user, and how the user interacts with an e-Service. From the user perspective e-Service can be said to consist mainly of two parts; functional components and interaction components.

User intentions have to be propagated through both of interaction components and functional components to achieve interaction with the e-Service. The technologies used with eServices are predominantly related to the interaction components of communications-enabling devices allowing the user to interact with the device. Examples of these are voice interfaces or text-entry interfaces. The functional components of those devices that enable communication of the device with e-Services such as data-exchange protocols and networks have to answer to both the demands of the e-Service and the interaction components, see Figure 2. Since they do not effect the users interaction with the e-Service to any great extent they are not in the scope of the method described.

To identify enablers of future e-Service the following steps are suggested:

\section{Analysis of forthcoming e-Services}

The analysis of existing and forthcoming services leads to the selection, definition, and categorization of the e-Services covered. Those could include services such as eHealth, eGovernment, eLearning, eCommerce, travel, and leisure, as these and other services are likely to affect older and disabled citizens and consumers.
2. Analysis of likely service interaction profiles for each eService category

The e-Services within the scope (result of task 1) will be analyzed in terms of their likely service interaction profiles. This is done by defining the service interaction styles an eService can be expected to employ. Table IV illustrates the underlying rationale of this step and lists biometrics, person-toperson real-time communication, web forms, application download, and information browsing as examples of e-Service interaction styles. The service interaction styles are then mapped onto user interaction styles such as gesture recognition, virtual reality, touch input, key input, and voice input (see Table V with examples).

3. Analysis of forthcoming interaction technologies (technology roadmaps)

Develop roadmaps of forthcoming user interface technologies are being developed by employing established R\&D procedures. During this step relevant interaction technologies for the e-Services defined in step 2 will be identified. Figure 1 shows a technology roadmap with example data for illustration purposes.

The basis for this work is desk and internet research as well as expertise from subject matter experts in the various fields. One obvious problem is that technologies being developed by commercial companies are classified until they are being released to the market in the form of new products. Interviews with R\&D staff of those companies are still worthwhile as they 
TABLE I.

\begin{tabular}{|c|c|c|c|c|c|c|}
\hline \multirow[b]{2}{*}{ e-Services } & \multicolumn{6}{|c|}{ Service Interaction Styles } \\
\hline & Biometrics & $\begin{array}{l}\text { Person- } \\
\text { Person }\end{array}$ & $\begin{array}{l}\text { Web } \\
\text { Forms }\end{array}$ & $\begin{array}{l}\text { Application } \\
\text { Download }\end{array}$ & $\begin{array}{c}\text { Information } \\
\text { Browsing }\end{array}$ & $\cdots$ \\
\hline ePayments & $x$ & & $x$ & $x$ & & \\
\hline eGovernment & $x$ & & $x$ & $x$ & $x$ & \\
\hline eHealth & $x$ & $x$ & $x$ & & $x$ & \\
\hline eLearning & & $x$ & $x$ & & $x$ & \\
\hline eTravelling & & & $x$ & & $x$ & \\
\hline$\ldots$ & & & & & & \\
\hline
\end{tabular}

TABLE II.

SERVICE-INTERACTION PROFILES

\begin{tabular}{|c|c|c|c|c|c|c|}
\hline \multirow{2}{*}{$\begin{array}{l}\text { Service-Interaction } \\
\text { Styles }\end{array}$} & \multicolumn{6}{|c|}{ User Interaction Styles } \\
\hline & $\begin{array}{c}\text { Gesture } \\
\text { recognition }\end{array}$ & $\begin{array}{l}\text { Virtual } \\
\text { reality }\end{array}$ & $\begin{array}{c}\text { Touch } \\
\text { input }\end{array}$ & Key input & $\begin{array}{l}\text { Voice } \\
\text { input }\end{array}$ & $\cdots$ \\
\hline Biometrics & & & $x$ & & $x$ & \\
\hline Person-Person & $x$ & $x$ & $x$ & $x$ & $x$ & \\
\hline Web Forms & & & & $x$ & $x$ & \\
\hline Application Download & & & & $x$ & & \\
\hline Information Browsing & $x$ & $x$ & $x$ & $x$ & $x$ & \\
\hline
\end{tabular}

are usually free to discuss their view on general trends of userinterface design and related technologies.

Another major source for information are conference papers and journal articles that report cutting edge developments.

For each user-interaction technology, a number of characteristics should be collected:

- A description of the technology, related technologies, and expected mass-market deployment.

- User requirements in terms of user capabilities required for making use of the technology.

- Benefits for all users and potential benefits for users with disabilities.

- Cultural issues.

- Deployment pros and cons.

- Solutions for overcoming the exclusion of disabled users, implementation requirements for the solution, and harmonization issues.

Standards on accessibility to ICT, such as [6] and [7] should be used as methodological references to ensure accessibility requirements of ICT-human interactions are covered.

Analyzing this data will result in finding interaction technologies with usability issues.
Matching of service interaction profiles and interaction technologies roadmap

In the fourth step, the services interaction profiles identified in step 2 are being mapped onto the interaction technologies identified in step 3. The resulting relation between e-Services and their possible interaction technologies can be used to identify solutions for design-for-all provisions required (see Table 4 with a representation of that process with example data).

5. Design-for-All provisions for new interaction technologies

The outcome of this step will be the definition of provisions that have to be made prior to or at the introduction of each new technology in order to enable the support of emerging eServices for older and/or disabled users and citizens.

\section{DISCUSSION}

ETSI STF 377 will publish an ETSI Guide (EG) that will allow designers and implementers of novel user-interface technologies or eServices to assess at a very early stage whether a proposed product or service potentially excludes elderly and/or disabled users and to learn about corrective solutions ideally to be applied as part of the mainstream design process prior to the market introduction of the device or service. The entire path from eService to individual provisions made for specific technologies is available for a number of eServices but can be easily applied for services not explicitly covered in the ETSI Guide. The work in progress can be 


\begin{tabular}{|c|}
\hline Technologies \\
\hline Audio input \\
\hline - Ambient noise reduction \\
\hline - Noise cancellation \\
\hline - $\quad$... other Ambient noise reduction \\
\hline - ... other Audio inputs \\
\hline Sensing technologies \\
\hline - Location sensing \\
\hline - $\quad$ GPS tracking \\
\hline - $\quad$ Passive RFID \\
\hline - $\quad$... other Location sensing \\
\hline - Anonymous presence sensing \\
\hline - $\quad$ PIR sensors \\
\hline - Fixed in-device cameras \\
\hline - Hand-held cameras \\
\hline - Wall-mounted cameras \\
\hline - $\quad . .$. other cameras \\
\hline - Infra-red beams \\
\hline - $\quad$... other Anonymous presence sensing \\
\hline - ... other Sensing technologies \\
\hline other technologies \\
\hline
\end{tabular}

followed under [3], the final document will be available for download at [4].

\section{ACKNOWLEDGMENT}

We thank the members of ETSI and other companies and individuals who provide us with useful input and comments to our work.

\section{REFERENCES}

[1] http://epp.eurostat.ec.europa.eu/portal/ page/portal/product details/publication?p product code=KS-NP-05038

[2]

ETSI (www.etsi.org)

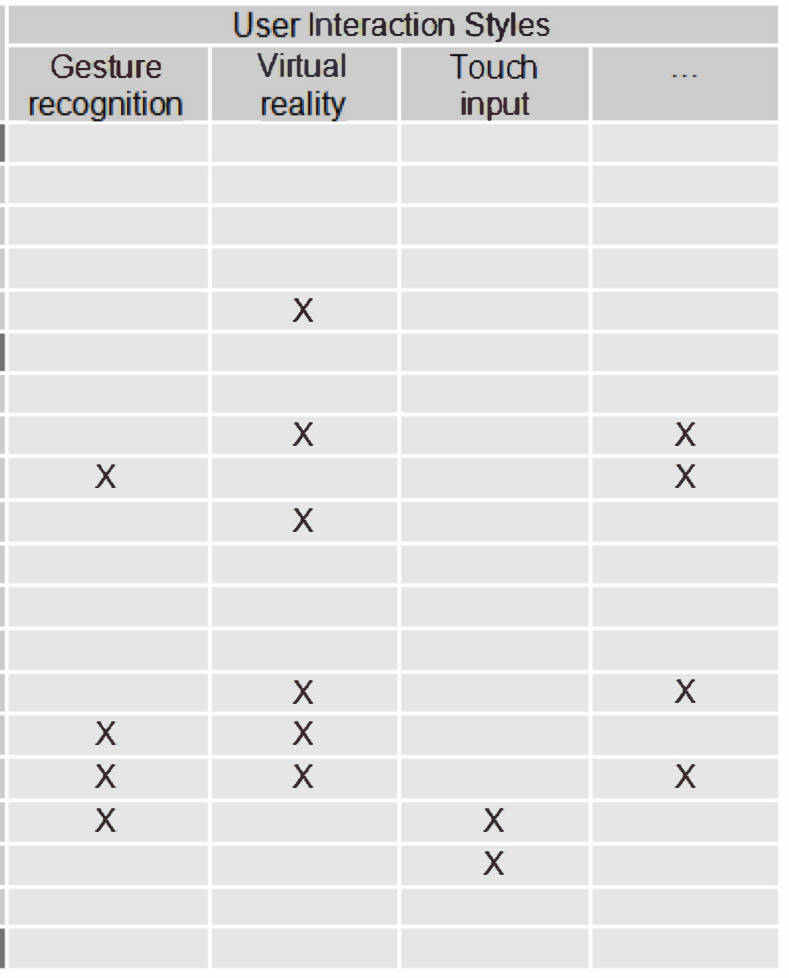

[3] http://portal.etsi.org/stfs/STF_HomePages/ STF377/STF377.asp

[4] ETSI Specialist Task Forces,

http://portal.etsi.org/stfs/process/home.asp

[5] C. Stephanidis, G. Salvendy et al (1998) Toward an Information Society for All: An International R\&D Agenda. International Journal of Human-Computer Interaction, Vol. 10(2), 1998, pp. 107-134

[6] ETSI EG 202116 (2002). Human Factors (HF); Guidelines for ICT products and services; "Design for All".

[7] ISO TR 29138-1. Information technology - Accessibility considerations for people with disabilities - Part 1: User needs summary 